\title{
Violence: a glossary
}

\section{Alison Rutherford, Anthony B Zwi, Natalie J Grove, Alexander Butchart}

Violence has been explicitly identified as a significant public health problem. This glossary clarifies widely used definitions and concepts of violence within the public health field, building on those promoted through the 2002 World Report on Violence and Health. We provide definitions and concepts that can be usefully applied to identify points for public health intervention to prevent the social and health impacts of violence.

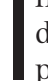
n 1996, the Forty-Ninth World Health Assembly declared violence a major and growing global public health problem. ${ }^{1}$ The initial and subsequently updated Global Burden of Disease study, the World Report on Violence and Health (WRVH) and the associated Global Campaign on Violence Prevention have together propelled violence onto the public health agenda. ${ }^{2-4}$ So too have recent debates on terrorism, gender-based violence, firearms control, youth violence and the upsurge of armed conflict in the Middle East.

This glossary clarifies widely used definitions and concepts of violence within the public health field, building on those promoted through the WRVH. Definitions of violence depend upon their purpose. For example, legal definitions of "assault" are more narrowly defined than the use of "assault" in hospital morbidity data collections, which is narrower than the meaning of assault in general parlance. Defining violence in different ways has implications for policy and practice. We use definitions and concepts from a range of sources that can be applied to identify public health consequences and preventive strategies.

The accompanying paper provides a framework in which to consider these definitions and concepts. ${ }^{5}$

\section{DEFINITIONS OF VIOLENCE An overarching definition}

Violence is defined by the World Health Organization in the WRVH as "the intentional use of physical force or power, threatened or actual, against oneself, another person, or against a group or community, that either results in or has a high likelihood of resulting in injury, death, psychological harm, maldevelopment or deprivation". ${ }^{4}$

This definition emphasises that a person or group must intend to use force or power against another person or group in order for an act to be classified as violent. Violence is thus distinguished from injury or harm that results from unintended actions and incidents. This definition also draws attention not only to the use of physical force but also to the use of threatened or actual power. Such power or force may be used against oneself, against an individual or against a group or community, as in gang violence or repression of ethnic groups. Violence is here defined not only as resulting in physical injury but as being present where psychological harm, maldevelopment or deprivation occurs; acts of omission or neglect, and not only of commission, can therefore be categorised as violent.

The WRVH divides violence into three categories according to who has committed the violence: selfdirected, interpersonal or collective; and into four further categories according to the nature of violence: physical, sexual, psychological or involving deprivation or neglect (fig 1).

Many forms of violence may occur simultaneously, so they are not mutually exclusive. For example, intimate partner violence may involve psychological, physical and sexual abuse, and collective violence often includes the use of rape as a weapon of war. ${ }^{67}$

\section{Self-directed violence}

Self-directed violence is a broad term that includes suicidal thoughts or action and forms of self-harm. The term "fatal suicidal behaviour" is often used for suicidal acts that result in death. "Non-fatal suicidal behaviour", "attempted suicide", "parasuicide" and "self harm" describe suicidal behaviour that does not result in death. "Suicidal ideation" is used clinically to describe contemplation of wilfully ending one's own life. "Selfmutilation" refers to direct and deliberate destruction or alteration of parts of the body without conscious suicidal intent.

\section{Interpersonal violence}

Interpersonal violence include acts of violence and intimidation that occur between family members, between intimate partners or between individuals, whether or not they are known to one another and where the violence is not specifically intended to further the aims of any group or cause. ${ }^{8}$ This category includes child maltreatment, youth violence, some forms of sexual violence and abuse of elders.

The International Classification of Diseases (ICD) codes, used around the world to code mortality and morbidity data, include mechanism of injury codes for assault, sexual assault, neglect, abandonment and maltreatment. ${ }^{9}$ These are sometimes grouped together and reported as "interpersonal violence". ${ }^{10}$ ICD codes also exist for selfinflicted violence and for injuries sustained through legal interventions or operations of war.

Abbreviations: ICD, International Classification of Diseases; WRVH, World Report on Violence and Health 


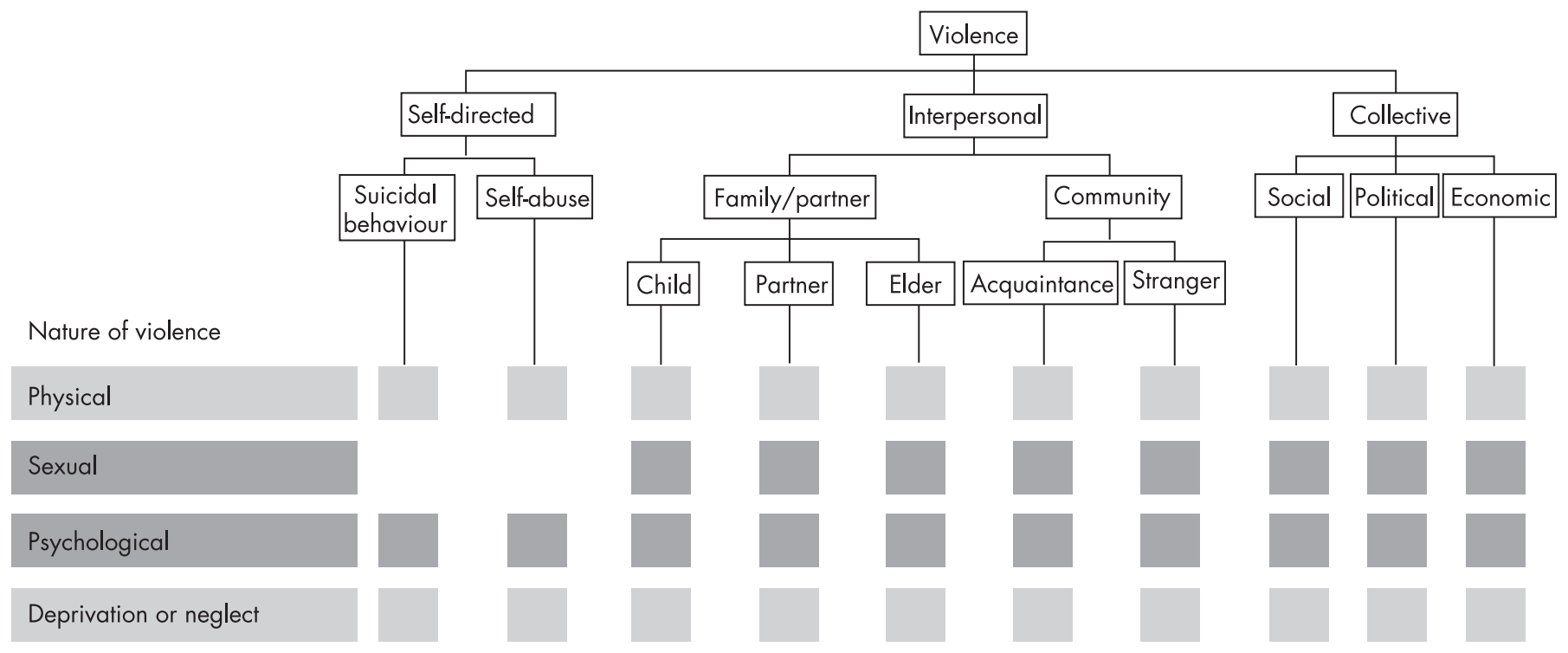

Figure 1 Typology of violence (from the World Report on Violence and Health ${ }^{4}$ ).

\section{Collective violence}

Collective violence has been defined as the "instrumental use of violence by people who identify themselves as members of a group...against another group or set of individuals, in order to achieve political, economic or social objectives". ${ }^{11}$ Collective violence includes war, terrorism and violent political conflict between or within states, violence perpetrated by states (genocide, torture, systematic abuses of human rights) and organised violent crime such as gang warfare. It may include all categories of violence, be these physical, sexual, psychological, or characterised by neglect or discrimination.

\section{Sexual violence}

Sexual violence can occur at an interpersonal or collective level. Sexual violence incorporates non-consensual sexual contact and non-consensual non-contact acts of a sexual nature, such as voyeurism and sexual harassment. ${ }^{12}$ Acts qualify as sexual violence if they are committed against someone who is unable to consent or refuse, for example because of age, disability, misuse of authority, violence or threats of violence.

Rape is defined as "physically forced or otherwise coerced penetration, even if slight, of the vulva or anus, using a penis, other body parts or an object". ${ }^{13}$ Sexual coercion is defined as "the act of forcing (or attempting to force) another individual through violence, threats, verbal insistence, deception, cultural expectations or economic circumstances to engage in sexual behaviour against his/her will". ${ }^{14}$

\section{Gender-based violence}

Gender-based violence is a term that recognises that violence occurs within the context of women's and girl's subordinate status in society, and serves to maintain this unequal balance of power. ${ }^{15}$ Gender-based violence is sometimes used interchangeably with "violence against women" although the latter is a more limited concept. The United Nations defines violence against women as "any act of gender-based violence that results in, or is likely to result in, physical, sexual or psychological harm or suffering to women, including threats of such acts, coercion or arbitrary deprivations of liberty, whether occurring in public or private life" ${ }^{\prime 16}$

Gender-based violence therefore includes violence against women occurring within the family, geographically or culturally specific forms of abuse such as female genital mutilation, "honour killings" and dowry-related violence as well as various forms of sexual violence, including rape during warfare, trafficking of women and forced prostitution. ${ }^{14}$ As mentioned earlier, these latter examples may be forms of collective violence where these abuses are directed not only against individuals but against entire groups. This is particularly so when sexual and gender-based violence are perpetrated in situations of conflict. ${ }^{17-20}$ Despite considerable attention, the lack of widely agreed definitions of the different forms of gender-based violence and violence against women, and the different ways in which these concepts are operationalised in the research context, limits the comparability of research findings. ${ }^{15}$

\section{Intimate partner violence}

"Intimate partner violence" refers to physical, sexual or psychological harm by a current or former partner or spouse. This type of violence can occur among heterosexual or same-sex couples and does not require sexual intimacy. Although women can be violent against their male partners and violence may be found in male-male and female-female partnerships, it is well accepted that the overwhelming burden of partner violence around the world is borne by women at the hands of men. ${ }^{4}$ Feminist theorists have studied the links between masculinities and violence, and identified the ways in which violence is used to bolster masculine identities, particularly in situations of poverty, and the implications of this for broader understandings of global violence. ${ }^{21-23}$

\section{Domestic violence}

"Domestic violence" is often used interchangeably with intimate partner violence. Domestic violence includes physical abuse, verbal abuse, economic abuse and social abuse. Hegarty et al suggest that "domestic violence can be better understood as a chronic syndrome characterised not only by episodes of physical violence but also by the emotional and psychological abuse the perpetrators use to maintain control over their partners". 24

\section{Family violence}

Family violence refers to child maltreatment, sibling violence, intimate partner violence and elder abuse. The concept of family violence is increasingly being used to draw attention to how each of the sub-types of family violence may cause or be a risk factor for the other subtypes, and how there may be 
common underlying risk factors at the levels of the family and the relationship between the family and the wider community and society. In turn, this suggests prevention opportunities that can help reduce the risk of all types of violence within the family by addressing the family and social systems. The interconnectedness of family violence, suicide, crime and drug and alcohol abuse as manifestations of intergenerational trauma and the importance of understanding historical contexts that produce family violence have been emphasised in Australia and in indigenous communities elsewhere. ${ }^{25} 26$

\section{Child maltreatment}

Child maltreatment and child abuse are sometimes used interchangeably. For example, the WHO Consultation on Child Abuse Prevention uses the following definition: "Child abuse or maltreatment constitutes all forms of physical and/or emotional ill-treatment, sexual abuse, neglect or negligent treatment or commercial or other exploitation, resulting in actual or potential harm to the child's health, survival, development or dignity in the context of a relationship of responsibility, trust or power" ${ }^{27}$

Some definitions consider as abused those children who have been inadvertently harmed through the actions of a parent or caregiver, while others require that harm to the child be intended for "abuse" to have occurred. ${ }^{28}$

Given that ideas about parenting are culturally contingent, concepts of what constitutes child maltreatment vary significantly between cultures. For example, corporal punishment of children is socially and legally accepted in many countries, while in others it is outlawed. ${ }^{28}$ Cultures continuously evolve and so harmful, culturally sanctioned practices have the potential to change over time.

\section{Youth violence}

Around the world age is a significant risk factor for becoming both a victim or a perpetrator of violence, with young males being particularly at risk. The World Health Organization defines youth violence as "homicide and non-fatal attacks perpetrated by or against a person aged 10-29 years of age" ${ }^{29}$ This definition explicitly includes young people as both victims and perpetrators, emphasising the increased exposure to violence young people experience as they pass through this life stage.

\section{Elder abuse}

Elder abuse may be an act of commission or omission and may be intentional or unintentional. As with other forms of abuse, it may be physical, psychological, financial, sexual or involve neglect. The International Network for the Prevention of Elder Abuse uses the following definition: "a single or repeated act, or lack of appropriate action, occurring within any relationship where there is an expectation of trust which causes harm or distress to an older person". ${ }^{30}$

\section{Workplace violence}

Workplace violence has received increased attention around the world in the last decade. Definitions vary in the emphasis they place on physical violence versus psychological violence; recent work emphasises the negative effects of both.

The International Labour Organization uses a definition of workplace violence adapted from the European Commission: "Incidents where staff are abused, threatened or assaulted in circumstances related to their work, including commuting to and from work, involving an explicit or implicit challenge to their safety, well being or health" ${ }^{31}$

Bullying lacks a consistent definition but is usually defined as persistent rather than isolated behaviour. Bullying within a workplace may involve threats to professional status, threats to personal standing, isolation, overwork and destabilisation. Within the health care professions, ambulance workers, nurses and workers with substantial face-to-face contact are particularly vulnerable to bullying. ${ }^{32}$

Harassment at work is any conduct based on age, disability, HIV status, sex, sexual orientation and other factors that is unreciprocated and unwanted and affects the dignity of men and women at work. ${ }^{31}$ Sexual harassment refers to "where any form of unwanted verbal, non-verbal or physical conduct of a sexual nature occurs, with the purpose or effect of violating the dignity of a person, in particular when creating an intimidating, hostile, degrading, humiliating or offensive environment" ${ }^{\prime \prime 3}$

\section{Structural violence}

"Structural violence" refers to the physical and psychological harm that result from exploitative and unjust social, political and economic systems. The apartheid system, based on racial discrimination in South Africa, is a classical case of structural violence in which the state set in place unjust laws and systems which disempowered, marginalised and disenfranchised the majority black population. These and related human rights violations are significant social determinants of ill health.

Structural violence is, however, often most pervasive because of its invisibility: "embedded in ubiquitous social structures (and) normalized by stable institutions and regular experience...structural inequities usually seem ordinary". ${ }^{34}$ Farmer, for example, demonstrated the link between the emergence and persistence of AIDS and TB in Haiti and their disproportionate impact on the poor to the enduring effects of European expansion, slavery and racism; economic dependence on the United States; and attempts to erase, or forget, this history. ${ }^{35}$ Forms of structural violence operate globally against women, children, indigenous peoples and those in poverty. ${ }^{34}$ Structural violence may both underlie and be an outcome of modern armed conflicts. ${ }^{34}$

\section{Armed conflict}

The term "armed conflict" is often used in preference to "war" given legal complexities surrounding definitions of war and the changing nature of violent political conflict. ${ }^{11}$ War typically suggests armed conflict between two states, but we are increasingly facing internal armed conflicts, wars within states, and often conflicts involving non-state actors such as private armies and locally armed militia. Conflicts in the Middle East have highlighted the immense impact on lives and livelihoods of both terrorism and massive armed interventions.

\section{New wars}

"New wars" describe conflicts where the boundaries between war, organised crime and wide-scale human rights abuse have blurred. ${ }^{36}$ A current example is in Darfur, Sudan, where ongoing collective violence has resulted from a group of militia, backed by the Sudanese state, using terror and repression to displace other communities and thereby enrich themselves through gaining access to key resources. Nearly 4 million people have been affected by displacement. ${ }^{37}$ Human rights abuses abound and the international community has been limited in its response.

\section{Complex emergencies}

A complex emergency is "a humanitarian crisis in a country, region or society where there is total or considerable breakdown of authority resulting from internal or external conflict and which requires an international response that goes beyond the mandate or capacity of a single agency and/or the ongoing United Nations country program".38 Complex emergencies result in dislocation of population, destruction of social networks and ecosystems, insecurity affecting civilians and 
others not involved in conflict and abuses of human rights. ${ }^{39}$ Complex emergencies may involve natural or man-made disasters, but the term is often used to describe violent conflict with major political implications. ${ }^{11}$ The health impacts typically result from both the direct effect of the violence as well as the additional layer of morbidity and mortality which results from food insecurity and infectious diseases, as recently seen in the Democratic Republic of Congo. ${ }^{41}$

\section{Terrorism}

Terrorism is a controversial and subjective term with multiple definitions, one of which relates to use of, or threat of, violence against civilians and the state, or symbols thereof, in order to create fear and achieve political, economic, religious or ideological goals. Concern has focused most recently on issues of biosecurity and the potential to use biological agents against the general population. Terrorism has been defined by a high level United Nations panel as "any act intended to cause death or bodily harm to civilians or non-combatants for the purpose of either intimidating a population or compelling a government or a government institution to do or not to do something" ${ }^{\prime \prime 2}$

The population health effects of terrorism vary considerably. Particularly important may be the psychological impact of widespread fear and anxiety and the implications of these for travel, use of and access to services, and psychosocial wellbeing more generally.

\section{Genocide}

Article 2 of the 1951 Convention on the Prevention and Punishment of the Crime of Genocide defines genocide as

\begin{abstract}
any of the following acts committed with intent to destroy, in whole or in part, a national, ethnical, racial or religious group, as such: (a) killing members of the group; (b) causing serious bodily or mental harm to members of the group; (c) deliberately inflicting on the group conditions of life calculated to bring about its physical destruction in whole or in part; (d) imposing measures intended to prevent births within the group; (e) forcibly transferring children of the group to another group. ${ }^{43}$
\end{abstract}

\section{THE PREVENTION OF VIOLENCE}

The most important outcome of focusing on violence and defining it clearly is the potential to more precisely understand its scale, forms and causes and to enhance the scope to intervene to prevent its occurrence or to modify its effects. Prevention activities can be classified by the stage during which prevention takes place (primary, secondary or tertiary prevention) as well as by its relationship to the population (universal, selective or indicated interventions).

\section{Primary prevention}

The primary prevention of violence aims to stop violent incidents occurring. Primary prevention is the most effective form of prevention but also the most difficult to achieve. Policy initiatives to address poverty and inequity could be classified as primary prevention activities in relation to violence, as could those directed at controlling the availability of firearms.

Primary prevention is often unattractive to politicians because upstream preventive activities are not visible unless they are linked with service provision. Sustained nurse homevisiting of mothers with young children is an evidence-based primary prevention strategy that does link with service provision and is widely acknowledged to improve outcomes for children and reduce their risk of becoming victims or perpetrators of abuse. ${ }^{44}$

\section{Secondary prevention}

Secondary prevention aims to minimise harm once a violent incident has occurred, focusing on immediate responses, such as emergency services or treatment for sexually transmitted diseases following rape. Secondary prevention could also include intervening in situations of high risk, such as reducing the risks of sexual exploitation in refugee camps or internally displaced person settings through better planning of facilities, better training of protection forces, and greater calls for accountability by those charged with the duty to protect victims of violence.

\section{Tertiary prevention}

Tertiary prevention aims to treat and rehabilitate victims and perpetrators. Approaches focus on long-term care in the wake of violence, such as rehabilitation and reintegration, and attempts to lessen trauma or reduce the long-term disability associated with violence. Examples include psychological therapies for abused children; screening and support services for victims of intimate partner, domestic or family violence; and specific recognition of the needs of survivors of torture.

\section{Universal interventions}

Universal interventions addressing violence are aimed at the general population, or groups within it (for example those of a certain gender or age bracket) without regard to individual risk. Examples include developing educational and training programs against bullying in schools, or reducing population alcohol consumption by regulating sales and increasing prices to prevent alcohol-related violence.

\section{Selective (or targeted) interventions}

Selective interventions focus on those at heightened risk of violence. For example, early intervention programs focusing on low-income single parents.

\section{Indicated interventions}

Indicated interventions focus on high-risk individuals who have detectable problems, such as perpetrators of domestic violence or sexual offenders. For example, some prisons conduct mandated programs for violent offenders.

\section{What this paper adds}

- This paper provides key definitions of major forms of violence.

- Common terms used in describing violence are explained.

- A comprehensive overview of why violence is important to public health is provided.

\section{Policy implications}

- Public health must engage with issues of violence.

- Improved definitions and precise description will aid surveillance, help determination of burden, and enhance response.

- Violence can no longer be relegated to some other sector - public health must engage and help shape a safer future. 


\section{CONCLUSION}

Violence is a significant public health problem and defies simple analysis. Defining violence in different ways has both moral and material consequences, such as whether or not a perpetrator is prosecuted, whether or not a prevention program is funded, or how a victim understands their situation. It is most important that public health practitioners understand the broad scope of violence and are able to identify points for successful intervention to prevent violence and its health and social impacts.

\section{Authors' affiliations}

Alison Rutherford, Anthony B Zwi, Natalie J Grove, School of Public Health and Community Medicine, University of New South Wales, Sydney, Australia

Alexander Butchart, Department of Injuries and Violence Prevention, World Health Organization, Geneva, Switzerland

Competing interests: AZ was co-editor of the World Report on Violence and Health. $A B$ works for the World Health Organization which campaigns and provides technical advice on violence prevention.

\section{REFERENCES}

1 World Health Assembly. Resolution WHA49.25 Prevention of violence: a public health priority, Forty-Ninth World Health Assembly, 1996. Geneva: WHO, 1996.

2 World Bank. World development report 1993: investing in health. New York: Oxford University Press, 1993.

3 Murray C, Lopez A, Mathers C, et al. The Global Burden of Disease 2000 project: aims, methods and data sources. Geneva: World Health Organization, 2001.

4 Krug E, Dahlberg L, Mercy J, et al. World report on violence and health. Geneva: World Health Organization, 2002.

5 Rutherford A, Zwi AB, Grove NJ, et al. Violence - a priority for public health? J Epidemiol Community Health. In press.

6 Turshen $M$. The political economy of rape: an analysis of systematic rape and sexual abuse of women during armed conflict in Africa. In: Clark FC, ed. Victims, perpetrators or actors? Gender, armed conflict and political violence. London: Zed Books, 2001:55-68.

7 Bouta T, Frerks G, Bannon I. Gender, conflict, and development. Washington: The World Bank, 2005.

8 Waters $\mathrm{H}$, Hyder A, Rajkotia Y, et al. The economic dimensions of interpersonal violence. Geneva: Department of Injuries and Violence Prevention, World Health Organization, 2004.

9 World Health Organization. International classification of diseases 10th edition. Geneva: World Health Organization, 2003.

10 Population Health Division. The health of the people of NSW: report of the Chief Health Officer 2004. Sydney: NSW Department of Health, 2004.

11 Zwi A, Garfield R, Loretti A. Collective violence. In: Krug E, Dahlberg L, Mercy J, et al, eds. World report on violence and health. Geneva: World Health Organization, 2002:213-40.

12 Basile KC, Saltzman LE. Sexual violence surveillance: uniform definitions and recommended data elements. Atlanta: National Center for Injury Prevention and Control, Centers for Disease Control and Prevention, 2002.

13 Jewkes R, Sen P, Garcia-Moreno C. Sexual violence. In: Krug E, Dahlberg L, Mercy J, et al, eds. World report on violence and health. Geneva: World Health Organization, 2002:147-82.

14 Krantz G, Garcia-Moreno C. Violence against women. J Epidemiol Community Health 2005;59:818-21.

15 Watts C, Zimmerman C. Violence against women: global scope and magnitude. Lancet 2002;359:1232-7.

16 United Nations. Declaration on the elimination of violence against women, United Nations General Assembly, 1993

17 UNHCR. Sexual violence against refugees: guidelines on prevention and response. Geneva: UNHCR, 1995
18 Amnesty International. Sierra Leone: rape and other forms of sexual violence against girls and women. London: Amnesty International, 2000.

19 Human Rights Watch. Shattered lives: sexual violence during the Rwandan genocide and its aftermath. New York: Human Rights Watch, 1996.

20 United Nations. Beiijing declaration and platform for action, Fourth World Conference on Women. New York: United Nations, 1995.

21 Dobash ER, Dobash R. Violent men and violent contexts. Rethinking violence against women. London: Sage, 1998.

22 Jewkes R. Intimate partner violence: causes and prevention. Lancet 2002;359:1423-9.

23 Brienes I, Connell R, Eide I. Male roles, masculinity and violence. Paris: UNESCO, 2000.

24 Hegarty K, Hindmarsh ED, Gilles MT. Domestic violence in Australia: definition, prevalence and nature of presentation in clinical practice. Med J Aust $2000 ; 173: 363-7$.

25 Blagg H. Crisis intervention in Aboriginal family violence. Canberra: Commonwealth of Australia, 2000

26 Anderson I. Understanding Indigenous violence. Aust N Z J Public Health 2002;26:408-9.

27 World Health Organization. Report of the Consultation on Child Abuse Prevention, 29-31 March, 1999. Geneva: World Health Organization, 1999.

28 Runyan D, Wattam C, lkeda R, et al. Child abuse and neglect by parents and other caregivers. In: Krug E, Dahlberg L, Mercy J, et al, eds. World report on violence and health. Geneva: World Health Organization, 2002:57-86.

29 Mercy JA, Butchart A, Farrington D, et al. Youth violence. In: Krug E, Dahlberg L, Mercy J, et al, eds. World report on violence and health. Geneva: World Health Organization, 2002:23-56.

30 Wolf $R$, Daichman L, Bennett G. Abuse of the elderly. In: Krug E, Dahlberg L, Mercy J, et al, eds. World report on violence and health. Geneva: World Health Organization, 2002:123-46.

31 International Labour Office/International Council of Nurses/World Health Organization/Public Services International. Framework guidelines for addressing workplace violence in the health sector. Geneva: International Labour Office, 2002.

32 Mayhew C, Chappell D. Violence in the workplace. Med J Aust 2005; 183(7):346-7.

33 European Parliament. Council Directive 2002/73/EC: implementation of the principle of equal treatment for men and women as regards access to employment, vocational training and promotion and working conditions. Brussels: European Parliament, 2002.

34 Winter DuNann D, Leighton D. Structural violence: introduction. In: Christie DJ, Wagner RV, Winter DuNann D, eds. Peace, conflict and violence:peace psychology for the 21 st century. New Jersey: Prentice Hall, 2001:99.

35 Farmer P. An anthropology of structural violence. Curr Anthropol 2004;45:305-25.

36 Kaldor M. New and old wars: organized violence in a global era. Cambridge: Polity Press, 1999

37 United Nations. Darfur humanitarian profile \# 22. Khartoum: Office of UN Deputy Special Representative of the UN Secretary-General for Sudan, 2006, www.humanitarianinfo.org/darfur/uploads/hprofile/2006/jan/ 1.\%20Narrative.pdf (accessed 3 June 2007).

38 UNHCR. Handbook for emergencies. Geneva: United Nations, 2001.

39 Leaning J. Introduction. In: Leaning J, Briggs SM, Chen LC, eds. Humanitarian crises: the medical and public health response. Cambridge: Harvard University Press, 1999:1-11.

40 Coghlan B, Brenna R, Ngoy P, et al. Mortality in the Democratic Republic of Congo: a nationwide survey. Lancet 2006;367:44-51.

41 Ghobarah $H$, Huth $P$, Russett $B$. The post-war public health effects of civil conflict. Soc Sci Med 2004;59:869-84.

42 United Nations. UN high level panel report. International Summit on Democracy, Terrorism and Security. Madrid 8-11 March 2005. http://english.safedemocracy.org/keynotes/un-high-level-panel-report.html (accessed 2 June 2007).

43 United Nations. Convention on the prevention and punishment of the crime of genocide, Adopted by Resolution 260 (III) A of the U.N. General Assembly on 9 December 1948; Entry into force: 12 January 1951, http:// www.preventgenocide.org/law/convention/text.htm\#II laccessed 2 June 2007).

44 Olds DL, Eckenrode J, Henderson Jr CR, et al. Long term effects of home visitation on maternal life course and child abuse and neglect: fifteen-year follow up of a randomized trial. J Am Med Assoc 1997:278:637-43. 